\title{
Predicting Falls Risk in Hospital; KPJ Seremban Experience
}

\author{
Maygala A, Primuhasa Putra SHA, Aziz AR, Ainol MR, Zainah J, Asrina A, Suzana K, Zainab MN, Nisha MB
}

KPJ Seremban Specialist Hospital, Seremban, Negeri Sembilan

\begin{abstract}
Introduction: Falls may result in injuries, prolonged hospitalization, increase in morbidity and mortality, incur cost to the individual and the healthcare system and increase potential litigation. Various hospital fall prevention programs such as Morse Fall Scale Assessment Tool have been implemented in the last decade; however most of the program had no sustained effects on falls reduction over extended period of time. Benchmarking from private hospitals showed patients fall increased by 27\% in 2008 as compared to 2007 (MPC report, 2008). There were 25 cases of falls in 2008 at KPJ Seremban Specialist Hospital. The objective of this program is to comply with The Joint Commission's National Patient Safety Goals 9, "reduce the risk of patient harm resulting from falls" and to formulate evidence based best clinical practice recommendations on assessment and prevention of falls in the hospital for all inpatients, outpatients, customers and staffs within hospital premises. Materials and Methods: Contributing factors were identified based on the retrospective analysis of falls from 1st.January 2008 to 30th September 2008. A fall risk assessment tool identified as KPJ FRAT (KPJ Fall Risk Assessment Tool) for inpatient was developed and various other strategies to reduce the risk of falls throughout the hospital premises were identified. Points of engagement for inpatient assessment using KPJ FRAT were on admission, transfer in or when there is a change in patients' condition. A prospective descriptive study was done and data was collected from 1st January 2009 till 31st December 2009 through interview with patients, healthcare providers and review of adverse event reports and medical records. Results: No of inpatients during this study were 37058 and there were 13 falls. The post implementation data reflects for every 1000 inpatient days the fall rate decreased to 4.3 falls. Conclusion: The use of KPJ FRAT and Fall Prevention program implemented throughout KPJ SSH has reduced the incidence of falls significantly by $48 \%$. This might be due to increase awareness among the staff, hospital wide policy to report all cases and the formation of patient safety committee to formulate policy and reinforce the implementation processes. Limitation of the study include under reporting and heavy workload.
\end{abstract}

KEYWORDS: Risk, falls, inhospital

Corresponding author;

Asrina Asri, Physiotherapist, KPJ Seremban Specialist Hospital, Lot 6219 \& 6220, Jalan Toman Satu, Kemayan Square,

70200 Seremban, Negeri Sembilan

e-mail: asrina@ssh.kpjhealth.com.my 